\title{
Prevalence and Spectrum of Fetal Congenital Anomalies: A Hospital Based Study from Mid-Western Part of Nepal
}

\author{
Khanal GP ${ }^{1}$, Sharma $\mathbf{P}^{2}$, Kayastha $\mathbf{P}^{3}$, Poudel $\mathbf{A}^{4}$ \\ ${ }^{1}$ Department of Radiology and Imaging, Pokhara Academy of Health Sciences, Pokhara, Nepal \\ ${ }^{2}$ Department of Radiology and Imaging, Manipal College of Medical Sciences, Pokhara, Nepal \\ ${ }^{3}$ Department of Radiology and Imaging, Institute of Medicine, Tribhuvan University Teaching Hospital, \\ Kathmandu, Nepal \\ ${ }^{4}$ Tribhuvan University, Institute of Medicine, Pokhara Nursing Campus, Pokhara, Nepal
}

Received: August 11, 2019

Accepted: October 1, 2019

Published: December 31,2019

Cite this paper:

Khanal GP, Sharma P, Kayastha P, Poudel A. Prevalence and Spectrum of Fetal Congenital Anomalies: A hospital based study from Mid-Western part of Nepal: A Hospital based study in Western Nepal. Nepalese Journal of Radiology 2019;9(14):2-9.http://dx.doi.org/10.3126/njr.v9i2.27413

\section{ABSTRACT}

Introduction: To estimate the prevalence and pattern of congenital anomalies through obstetric ultrasound on pregnant women visiting Rapti sub-regional hospital, Ghorahi, Dang, Nepal.

Methods: A descriptive cross sectional study was conducted among 10,380 pregnant women visiting Radiology department of Rapti sub-regional hospital from January 2016 to July 2017. The findings of transabdominal ultrasonography (USG) performed by Radiologist and information regarding women's age and gestational age were recorded. The images of any significant cases were also saved. Data were analyzed based on study objectives using descriptive statistics such as frequency, percentage, mean, range and standard deviation. The classification of the malformation was done based on the anatomical system.

Results: Out of 10,380 ultrasound performed during the study period, 106 (1.02\%) pregnant women presented with different congenital anomalies. The antenatal prevalence of congenital anomalies was 10.21 per 1000 pregnant women. The mean maternal age was $25.9 \pm 4.80$ years. Regarding gestation age, $87(82.1 \%)$ anomalies were detected at second trimester of pregnancy. Most commonly involved body system was central nervous system 51 (48.1\%), followed by cardiovascular system $12(11.3 \%)$, musculoskeletal system $10(9.4 \%)$, gastrointestinal system 5 $(4.7 \%)$, respiratory system $5(4.7 \%)$, genitourinary system $4(3.8 \%)$. Other anomalies were cystic hygroma $9(8.4 \%)$, hydrops fetalis 4 (3.8\%), cleft lip $3(2.8 \%)$, pelvic cystic lesion $2(1.8 \%)$ and conjoined twins $1(0.9 \%)$.

Conclusion: The prevalence of congenital anomalies is high in mid-western part of Nepal. Central nervous system anomalies were more common than other anomalies.

Keywords: Birth Defects; Gestational Age; Hydrops Fetalis

\author{
Correspondence to: Dr. Gopal Prasad Khanal \\ Department of Radiology and Imaging \\ Pokhara Academy of Health Sciences \\ Pokhara, Nepal \\ E-mail: Khanallgopal@gmail.com
}

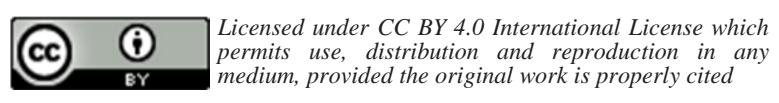




\section{INTRODUCTION}

Congenital anomalies, also commonly referred to as birth defects, congenital disorders and congenital malformations are the vital causes of disability, chronic illness, and prenatal mortality and morbidity in many countries. Congenital anomalies encompass a wide array of structural and functional abnormalities that can occur in isolation (i.e. single defect) or as a group of defects (i.e. multiple defects). ${ }^{1}$ According to World Health Organization report, about 303 thousand newborn deaths occur within 4 weeks of birth every year worldwide from congenital anomalies. ${ }^{1}$ Every year, about 3-6\% of infants worldwide are born with a serious birth defects. ${ }^{3}$

Worldwide surveys have shown that birth prevalence of congenital anomalies varies greatly from country to country. Major congenital malformations are reported in at least $2 \%$ of pregnancies in United Kingdom. ${ }^{4,5}$ In China, $1.03 \%$ of neonates are born with congenital anomalies while in India the incidence of $2.3 \%$ has been documented. ${ }^{6,7}$ The study from Nepal showed the prevalence of 52.0 (95\% CI: 44.0-61.0) per 10,000 children. ${ }^{8}$

Whereas according to Nepal Demographic and Health Survey, congenital malformations and deformities account for $7 \%$ of all neonatal deaths. ${ }^{9}$ The most common, severe congenotal anomalies are heart edfects, neural tube defects and Down syndrome. ${ }^{2}$

During the last decades an increasing number of congenital malformations have been diagnosed prenatally by ultrasound investigations. Approximately $3 \%$ of pregnancies show fetal structural anomalies in a sonogram, which range from a single minor defect to severe multisystem anomalies. ${ }^{10}$ Better quality of ultrasound machine, improved competency of radiologist and appropriate policy regarding number and time of examination to perform has helped to improve the detection rate of fetal abnormalities. 5

In Nepal, access to ultrasonography (USG) is very limited particularly in rural settings. Only one-quarter of women in rural Nepal received an obstetric ultrasonographic examination during their most recent pregnancy. ${ }^{11}$ Therefore, the true magnitude of antenatal prevalence of congenital malformations in Nepal is unknown. Furthermore, the country also lacks the nationally representative data on such issues. The present study was conducted at one of the biggest referral hospital of Nepal which provides access to nearby rural population too. Many obstetric scans are performed annually in this hospital but the exact antenatal prevalence of congenital malformations is unknown. Therefore the current study aims to establish the prevalence and pattern of congenital anomalies through obstetric ultrasound, in unselected population visiting Rapti sub-regional hospital.

\section{METHODS}

A descriptive cross sectional study was conducted at radiology department of Rapti sub-regional hospital, Ghorahi, Dang district of Nepal. Recently this hospital has been upgraded into medical college and named as Rapti Academy of Health Sciences. Ghorahi is the seventh largest city and sub-metropolitan city of Nepal which lies in Province No.5 in the mid-western part of Nepal. It is the only one biggest hospital of that area which provides gateway to the surrounding regions of Rolpa, Pyuthan, Salyan and Rukum. So, the hospital provides services to the large number of people from different districts too. The hospital is equipped with the latest diagnostic and therapeutic facilities. Every year about $9,000-10,000$ routine ultrasound takes place in the radiology department of this hospital out of which 6,000-7,000 are obstetric cases.

The study population consisted of pregnant women seeking obstetric services at Rapti sub-regional hospital. Pregnant women were consecutively referred to Radiology department from the outpatient and inpatient departments of Obstetrics and Gynecology of the same hospital and other clinics within 
the hospital vicinity from January 2016 to July 2017. Eligible patients comprised all the pregnant women who were equal to or greater than 10 weeks of gestation. The Radiologist performed transabdominal USG ona 'Samsung R7' machine using convex probe after taking verbal consent from the patient. The purpose of the study was explained to the patient and confidentiality of results assured. A standard protocol was used for scanning the head, face, chest, heart, diaphragm, abdominal wall, stomach, kidneys, bladder, spine and limbs. The result of transabdominal USG examination and information regarding women's age and gestational age were entered in a database and selected images were printed.

Statistical analysis was done using statistical package for social sciences version 20. Data were analyzed based on study objectives and using descriptive statistics such as frequency, percentage, mean, range and standard deviation.

\section{RESULTS}

During the study period of January 2016 to July 2017, a total of 10,380 prenatal USG were done. Out of these, $106(1.02 \%)$ pregnant women presented with different congenital anomalies. Maternal age parameter revealed that out of 106 women having congenital abnormalities in the fetus, the majority 39 (36.8\%) were between 26-30 years old followed by 21-25 years 33 $(31.1 \%)$ (Table 1$)$. The mean maternal age was $25.9 \pm 4.80$ years. Regarding gestational age, $11(10.4 \%)$ anomalies were detected at first trimester, $87(82.1 \%)$ at second trimester and 8 $(7.5 \%)$ at third trimester of pregnancy.

Most commonly involved system was central nervous system 51 (48.1\%) (Figure 1). Out of which, maximum number had hydrocephalus $14(27.4 \%)$ and anencephaly 10 (19.6\%). This is followed by cardiovascular system 12 (11.3\%), musculoskeletal system 10 (9.4\%), gastrointestinal system $5(4.7 \%)$, respiratory system $5(4.7 \%)$ and genitourinary system 4 (3.8\%). Other anomalies were cystic hygroma $9(8.4 \%)$ (Figure 3b), hydrops fetalis $4(3.8 \%)$
(Figure 3a), cleft lip 3 (2.8\%), pelvic cystic lesion $2(1.8 \%)$ and conjoined twins $1(0.9 \%)$ (Figure 2) (Table 2). Amelia a rare disease was also found in our study. (Figure 4)

\section{Table 1. Frequency of congenital malformation according to age of the pregnant women}

Maternal age $\quad$ Frequency of congeniin years tal anomalies

\begin{tabular}{|c|c|}
\hline $15-20$ & $17(16 \%)$ \\
\hline $21-25$ & $33(31.1 \%)$ \\
\hline $26-30$ & $39(36.8 \%)$ \\
\hline $31-35$ & $16(15.1 \%)$ \\
\hline $35-40$ & $1(0.9 \%)$ \\
\hline Total & 106 \\
\hline
\end{tabular}

Table 2. Spectrum of congenital anomalies according to bodv sustem

\begin{tabular}{|c|c|c|}
\hline System & Anomalies & Frequency \\
\hline \multirow{14}{*}{$\begin{array}{c}\text { Central } \\
\text { Nervous System }\end{array}$} & Hydrocephalus & 14 \\
\hline & & \\
\hline & Anencephaly & 10 \\
\hline & Chiari malformation II & 4 \\
\hline & Holoprosencephaly & 4 \\
\hline & $\begin{array}{l}\text { Dandy Walker } \\
\text { malformation }\end{array}$ & 3 \\
\hline & Microcephaly & 3 \\
\hline & Encephalocele & 3 \\
\hline & Acrania & 3 \\
\hline & Porencephalic cyst & 2 \\
\hline & Sacrococcygeal teratoma & 2 \\
\hline & Choroid plexus papilloma & 1 \\
\hline & Schizencephaly & 1 \\
\hline & Arachnoid cyst & 1 \\
\hline \multirow{6}{*}{$\begin{array}{c}\text { Cardiovascular } \\
\text { System }\end{array}$} & Cardiomegaly & 4 \\
\hline & Ebstein anomaly & 2 \\
\hline & Venticular septal defect & 2 \\
\hline & Hypoplastic left ventricle & 2 \\
\hline & Hypoplastic right ventricle & 1 \\
\hline & $\begin{array}{l}\text { Transposition of great } \\
\text { arteries }\end{array}$ & 1 \\
\hline $\begin{array}{l}\text { Musculoskeletal } \\
\text { System }\end{array}$ & Club foot unilateral & 4 \\
\hline
\end{tabular}




\begin{tabular}{|c|c|c|}
\hline & Club foot bilateral & 2 \\
\hline & Club hand bilateral & 2 \\
\hline & $\begin{array}{c}\text { Bilateral absence of upper } \\
\text { limbs (Figure. 4) }\end{array}$ & 1 \\
\hline $\begin{array}{c}\text { Gastointestinal } \\
\text { System }\end{array}$ & Achondroplasia & 1 \\
\hline & Diaphragmatic hernia & 3 \\
\hline & Choledochal cyst & 1 \\
\hline $\begin{array}{c}\text { Respiratory } \\
\text { system }\end{array}$ & $\begin{array}{c}\text { Cystic adenomatoid } \\
\text { malformation }\end{array}$ & 2 \\
\hline & Hypoplastic lung & 1 \\
\hline & Pleuraleffusion unilateral & 1 \\
\hline & Pleural effusion bilateral & 1 \\
\hline Genitourinary & $\begin{array}{c}\text { Multicystic dysplastic } \\
\text { kidney }\end{array}$ & 2 \\
\hline system & Autosomal recessive \\
disorder & 1 \\
\hline & Absent kidney & 1 \\
\hline Others & Cystic hygroma & 9 \\
\hline & Hydrops fetalis & 4 \\
\hline & Cleft lip & 3 \\
\hline TOTAL & Pelvic cystic lesion & 2 \\
\hline & Conjoined twins & 1 \\
\hline & & 106 \\
\hline
\end{tabular}
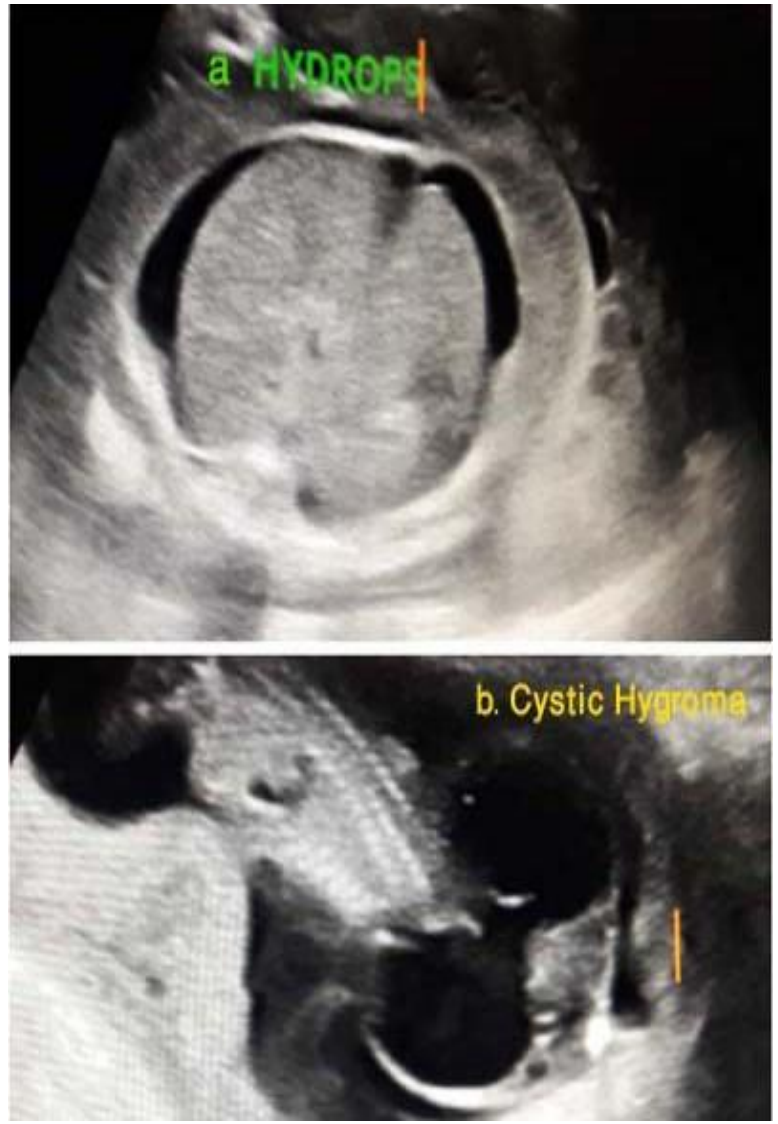

Figure 3: Ultrasound image showing $\mathbf{3 a}$. Hydropsfetalis, 3b. Cystic hygroma.
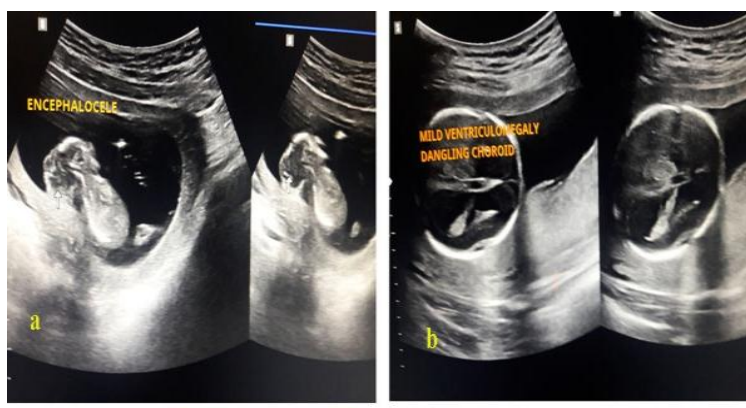
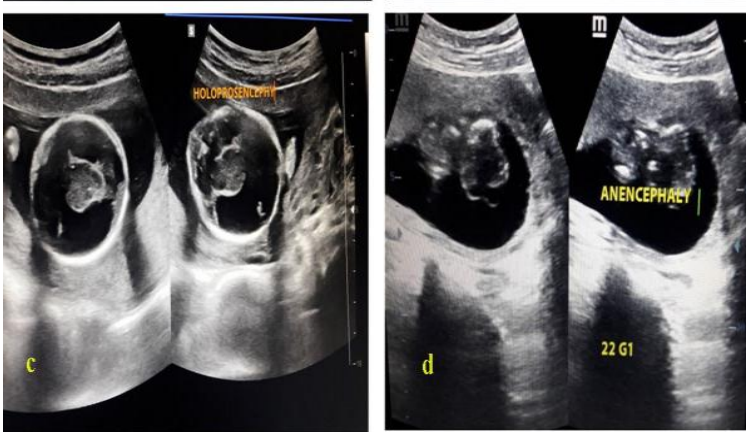

Figure 1: Ultrasound image showing fetal Central Nervous System anomalies 1a.Encephalocele1b. Ventriculomegaly 1c.Holoprosencephaly 1d. Anencephaly.

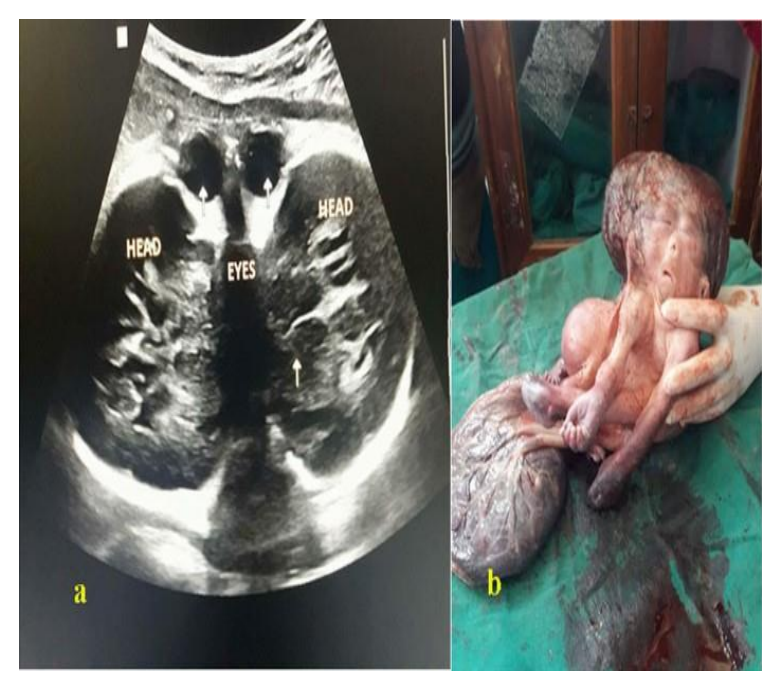

Figure 2: 2a. Ultrasound image showing siamese twins at 30 weeks of gestation. $2 \boldsymbol{b}$. image of siamese twins (Craniothoracopagus) after termination of pregnancy. 


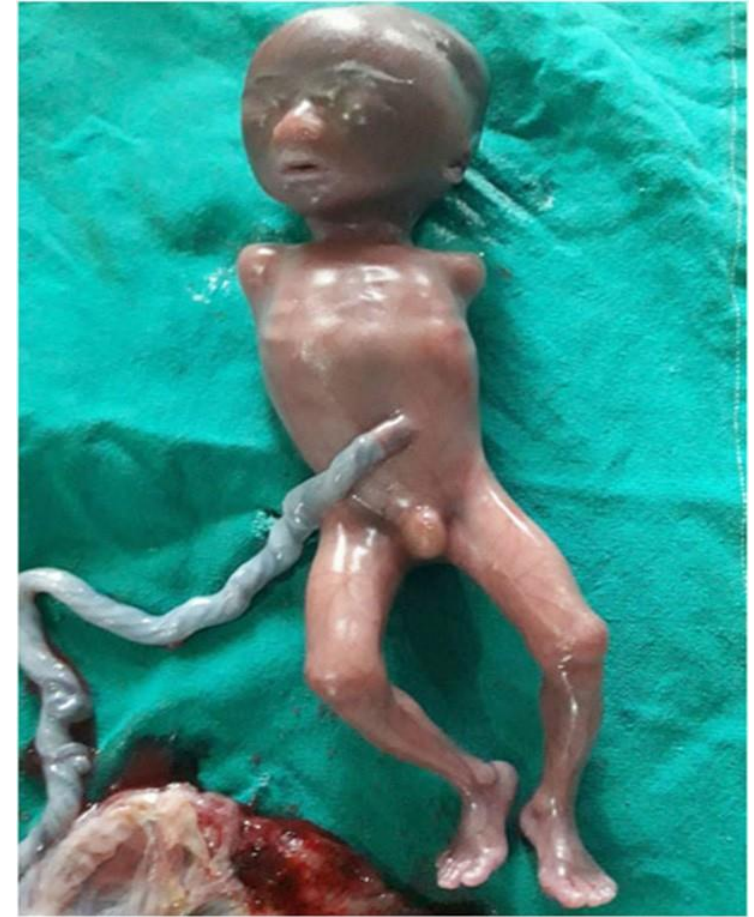

Figure 4: Image of dead fetus with absence of upper bilateral limbs (Amelia).

\section{DISCUSSION}

Congenital anomaly is a global health issue and plays a major role in perinatal mortality and morbidity, as well as childhood death, chronic illness and disability. In this study, out of 10,380 prenatal USG done in Radiology department of Rapti sub-regional hospital, Ghorahi, Dang, 106 (1.02\%) pregnant women were diagnosed as having congenital anomalies. This prevalence corresponds to the study of Wong et al. ${ }^{12} 1.01 \%$, Souka et al. ${ }^{13} 1.21 \%$. Higher prevalence was observed in some other studies like Becker et al. ${ }^{14}$ $2.8 \%$, Sallout et al. ${ }^{15} 2.79 \%$. This disparity in the rate of prenatal diagnosis of congenital malformations might be due to areas of the study in which some studies were conducted in referral centers. Moreover, screening policies, laws regarding the upper gestational age limit for termination, accessibility of advanced services, technology and skills have improved the early detection of anomalies. Other reasons for these variations might be due to the effects of socio-demographic factors and pregnant women's attitude towards screening in various parts of the world.

Mean maternal age at the time of diagnosis was $25.9 \pm 4.80$ years which has been supported by other studies. ${ }^{16}$ Though the studies have laid stress that first trimester ultrasound can detect half of fetal malformations in the present study only $10.4 \%$ of anomalies were detected in first trimester and more than three fourth $(82.1 \%)$ of the cases were detected in second trimester of pregnancy. ${ }^{5,17}$ This might be due to the fact that among those who had malformations detected at second trimester, more than half of the patients had no prior ultrasound performed at first trimester. It reflects the existing unawareness and vacuum of knowledge in patients. Another important reality is that some cases were missed and this missing out of an anomaly may be because of scarcity of good resolution machines, busy schedules, and lack of expertise as well. Study conducted in India also reported detection of only $1.6 \%$ of anomalies at first trimester and more than half of the anomalies were identified after 20 weeks of gestation. ${ }^{18}$

In the present study, almost half $51(48.1 \%)$ of the anomalies were of central nervous system, with higher frequencies of hydrocephalus followed by anencephaly. Other anomalies were related to cardiovascular system 12 (11.3\%), musculoskeletal system 10 (9.4\%), gastrointestinal system $5(4.7 \%)$, respiratory system $5(4.7 \%)$ and genitourinary system 4 $(3.8 \%)$. Miscellaneous category $19(17.9 \%)$ included cystic hygroma 9 (8.4\%), hydrops fetalis $4(3.8 \%)$, cleft lip $3(2.8 \%)$, pelvic cystic lesion $2(1.8 \%)$ and conjoined twins $1(0.9 \%)$. In most of the studies, central nervous system anomalies appear to be the most common systemic congenital anomalies. ${ }^{18}$ The incidence of central nervous system anomaly observed in this study (49.13/10000 women) was almost similar to the study reported by Atkinson et al. ${ }^{19}$ (44/10000 women). A study from Nepal also found central nervous system anomalies as the most common with higher frequencies 
of anencephaly followed by hydrocephalus and meningomyelocele and other major defects were related to gastrointestinal, musculoskeletal and genitourinary system. ${ }^{20}$ Similarly in the present study the incidence of cardiac anomalies was 13.48/10000 pregnancies which was slightly lower than the data from other studies. ${ }^{21,22}$ Although technical advancement has improved the accuracy of prenatal ultrasound some abnormalities can be missed. Therefore, suspected heart anomalies require more comprehensive evaluation using fetal echocardiography. ${ }^{23}$

According to recent literature the prevalence of congenital limb abnormalities is 1 in 1600 live births; the incidence is higher in the upper limbs compared to the lower limbs. ${ }^{24}$ In our study sample, a rare defect congenital absence of bilateral upper limbs or Amelia was also detected through routine ultrasound examination with the overall detection of 1 in 10,380 pregnancies. Data on the prevalence of Amelia are scarce, however few studies have reported the prevalence to be ranging from 0.95 to 1.71 per 100,000 births..$^{25,26,27}$ Furthermore, a complex rare malformation conjoined twins also known as Siamese twins was also identified on our routine ultrasound examination. Literature suggests the prevalence of this rare malformation to be 1 in 50,000 to 1 in 100,000 births. ${ }^{28}$ However, our study shows the prevalence to be 1 in 10,380 pregnancies. The couple were informed about the ultrasound findings and counseled about management options. They decided to terminate the pregnancy.

According to The Fetal Medicine Foundation, cystic hygromas affect 1 in 800 pregnancies and 1 in 8,000 live births. It has been associated with fetal aneuploidy, hydrops fetalis, structural malformations and intrauterine fetal death. ${ }^{29}$ Similarly, the incidence of hydrops fetalis is reported to be 0.3 to 2.4 per 1,000 live births. ${ }^{30}$ In the present study, the incidence of cystic hygromas and hydropsfetalis was 0.86 and 0.38 per 1,000 pregnancies respectively. Out of 106 anomalies detected in prenatal ultrasound $9(8.4 \%)$ were cystic hygroma and $4(3.8 \%)$ were hydrops fetalis.

\section{CONCLUSION}

Based on our result we concluded that the prevalence of congenital anomalies is high in mid-western part of Nepal. Antenatal ultrasound examination at first and second trimester is beneficial for detection of significant number of congenital anomalies and even rare anomalies can be identified. Early detection of major anomalies will offer to the parents the option of an earlier, safer and psychologically less traumatic termination of the pregnancy and further helps in planning interventions and necessary management. It avoids unnecessary expenditure as well as reduces mental, physical and psychological trauma to family of carrying a handicapped child.

It is recommended that, there is a need for more extensive, nationwide screening studies to determine the prevalence, types and distribution of congenital anomaliesin Nepalese population. Furthermore, studies assessing possible causes of congenital anomalies are also warranted. In addition, healthcare awareness campaigns on importance of routine obstetric ultrasound should be launched at all publicsectors.

\section{CONFLICT OF INTEREST}

None

\section{SOURCES OF FUNDING}

None

\section{REFERENCES}

1. DeSilva M, Munoz FM, Mcmillan Met al. Congenital anomalies: case definition and guidelines for data collection, analysis, and presentation of immunization safety data. Vaccine 2016;34(49):6015. https:// 
doi.org/10.1016/j.vaccine.2016.03.047

2. World Health Organization. Congenital anomalies. 2016. Available from: https:// www.who.int/news-room/fact-sheets/ detail/congenital-anomalies [Accessed 14th June 2018].

3. Centers for Disease Control and Prevention. World Birth Defects Day. 2019. Available from: https://www.cdc. gov/features/birth-defects-day/index. html [Accessed 13th April 2018].

4. Moore J, Bhide A. Ultrasound prenatal diagnosis of structural abnormalities. Obstet Gynaecol Reprod Med 2009;19(12):333-338. $\quad$ https://doi. org/10.1016/j.ogrm.2009.09.005

5. Curado J, Bhide A. The use of ultrasound in the antenatal diagnosis of structural abnormalities. Obstet Gynaecol Reprod Med 2018; 28(10):301-307. https://doi. org/10.1016/j.ogrm.2018.09.005

6. Luo XL, Zhang WY. Obstetrical disease spectrum in China: An epidemiological study of 111,767 cases in 2011. Chin Med J 2015;128(9):1137- 1146. https:// doi.org/10.4103/0366-6999.156076

7. Bhide P, Gund P, Kar A. Prevalence of Congenital Anomalies in an Indian Maternal Cohort: Healthcare, Prevention, and Surveillance Implications. PLoS One 2016;11(11):e0166408. https://doi. org/10.1371/journal.pone.0166408

8. Bhandari S, Sayami JT, K C RR, Banjara MR. Prevalence of congenital defects including selected neural tube defects in Nepal: results from a health survey. BMC Pediatr 2015;15(1):133. https:// doi.org/10.1186/s12887-015-0453-1

9. Ministry of Health Nepal, New ERA, ICF. Nepal Demographic and Health Survey 2016. Kathmandu, Nepal: Ministry of Health Nepal. 2017. Available from: https://www.dhsprogram.com/pubs/pdf/ fr336/fr336.pdf [Accessed 10th June 2019].

10. Onyambu CK, Tharamba NM. Screening for congenital fetal anomalies in low risk pregnancy: the Kenyatta National Hospital experience. BMC Pregnancy Childbirth 2018;18(1):180-9. https://doi. org/10.1186/s12884-018-1824-Z

11. Kozuki N, Katz J, Khatry SK, Tielsch JM, LeClerq SC, Mullany LC. Community survey on awareness and use of obstetric ultrasonography in rural Sarlahi District, Nepal. Int J Gynaecol Obstet 2016;134(2):126-130. https://doi. org/10.1016/j.ijgo.2016.01.015

12. Wong SF, Welsh A, Chan FY. Outcome of a routine ultrasound screening program in a tertiary center in Australia. Int J Gynaecol Obstet 2004;87(2):153$154 . \quad$ https://doi.org/10.1016/j. ijgo.2004.06.022

13. Souka AP, Pilalis A, Kavalakis I et al. Screening for major structural abnormalities at the 11 to 14 week ultrasound scan. AJOG 2006;194(2):393$396 . \quad$ https://doi.org/10.1016/j. ajog.2005.08.032

14. Becker R, Wegner RD. Detailed screening for fetal anomalies and cardiac defects at the 11-13 week scan. Ultrasound Obstet Gynecol 2006;27(6):613-618. https:// doi.org/10.1002/uog.2709

15. Sallout BI, Al Hoshan MS, Attyyaa RA, Al Suleimat AA. Antenatal diagnosis, prevalence and outcome of major congenital anomalies in Saudi Arabia: a hospital-based study. Annals of Saudi medicine 2008;28(4):272-276. https:// doi.org/10.5144/0256-4947.2008.272

16. Sallout B, Obedat N, Shakeel F, Mansoor A, Walker M, Al-Badr A. Prevalence of major congenital anomalies at King Fahad Medical City in Saudi Arabia: a tertiary care centre-based study. Annals of Saudi medicine 2015;35(5):343351. $\quad$ https://doi.org/10.5144/0256$\underline{4947.2015 .343}$

17. Rossi AC, Prefumo F. Accuracy of ultrasonography at 11-14 weeks of gestation for detection of fetal structural anomalies: a systematic review. 
Obstet Gynecol 2013;122(6):1160-

$1167 . \quad$ https://doi.org/10.1097/ AOG.0000000000000015

18. Kashyap N, Pradhan M, Singh N, Yadav S. Early detection of fetal malformation, a long distance yet to cover! Present status and potential of first trimester ultrasonography in detection of fetal congenital malformation in a developing country: experience at a Tertiary Care Centre in India. $J$ Pregnancy 2015;2015:623059. https://doi. org/10.1155/2015/623059

19. Atkinson DE, Amin F, Russell S, D'Souza SW. Fetal congenital anomalies diagnosed by ultrasound in Asian and non-Asian women. J Obstet Gynaecol 2008;28(7):678-682. $\quad$ https://doi. org/10.1080/01443610802463710

20. Shrestha S, Dwa Y, Jaiswal P,Parmar B. Congenital anomalies in antenatal ultrasound scan at a tertiary care teaching hospital. JPAHS 2018;5(1):26-30. https:// doi.org/10.3126/jpahs.v5i1.24038

21. Tegnander E, Williams W, Johansen OJ, Blaas HG, Eik-Nes SH. Prenatal detection of heart defects in a nonselected population of 30149 fetusesdetection rates and outcome. Ultrasound Obstet Gynecol ;27(3):252-265. https:// doi.org/10.1002/uog.2710

22. Carvalho JS, Mavrides E, Shinebourne EA, Campbell S, Thilaganathan B. Improving the effectiveness of routine prenatal screening for major congenital heart defects. Heart 2002;88(4):387-391. https://doi.org/10.1136/heart.88.4.387

23. Lee W, Allan L, Carvalho JS, Chaoui R et al. ISUOG Fetal Echocardiography Task Force. ISUOG consensus statement: what constitutes a fetal echocardiogram?. Ultrasound Obstet Gynecol;32(2):239-242. https://doi. org/10.1002/uog.6115

24. Ermito S, Dinatale A, Carrara S, Cavaliere A, Imbruglia L, Recupero S. Prenatal diagnosis of limb abnormalities: role of fetal ultrasonography. $J$ Prenat Med 2009;3(2):18(22). Available from: https://www.ncbi.nlm.nih.gov/pmc/ articles/PMC3279100/ [Accessed 21st March 2018].

25. Bermejo-Sánchez E, Cuevas L, Amar E et al. Amelia: a multi-center descriptive epidemiologic study in a large dataset from the International Clearing house for Birth Defects Surveillance and Research, and overview of the literature. Am J Med Genet C Semin Med Genet ;157(4):288$304 . \quad$ https://doi.org/10.1002/ ajmg.c.30319

26. Källén B, Rahmani TMZ, Winberg J. Infants with congenital limb reduction registered in the Swedish register of congenital malformations. Teratology 1984;29(1):73-85. https://doi. org/10.1002/tera.1420290109

27. Castilla EE, Cavalcanti D, Dutra M, López-Camelo J, Paz J, Gadow

E. Limb reduction defects in South America. $\mathrm{Br} \quad \mathrm{J}$ ObstetGynaecol 1995;102(5):393-400. $\quad$ https://doi. org/10.1111/j.1471-0528.1995. tb11292.x

28. Mutchinick OM, Luna-Muñoz L, Amar E et al. Conjoined twins: a worldwide collaborative epidemiological study of the International Clearinghouse for Birth Defects Surveillance and Research. Am J Med Genet C Semin Med Genet 2011;157(4):274-287. https://doi. org/10.1002/ajmg.c.30321

29. Chen YN, Chen CP, Lin CJ, Chen SW. Prenatal Ultrasound Evaluation and Outcome of Pregnancy with Fetal Cystic Hygromas and Lymphangiomas. J Med Ultrasound 2017;25(1):12-15. https:// doi.org/10.1016/j.jmu.2017.02.001

30. Yeom W, Paik ES, An JJ et al. Clinical characteristics and perinatal outcome of fetal hydrops. Obstet gynecol sci 2015;58(2):90-97. https://doi. org/10.5468/ogs.2015.58.2.90 